\title{
IJEVG and CDQ editors' joint statement on the second special international issues
}

\author{
Raoul Van Esbroeck · Jerry Trusty
}

Published online: 1 July 2009

(C) Springer/National Career Development Association (NCDA) 2009

In 2005, the first special international issues of the Career Development Quarterly (CDQ) and the International Journal for Educational and Vocational Guidance (IJEVG) were published. These companion issues presented elements of the International IAEVG-NCDA Symposium held in San Francisco in 2004. Taken together, the two issues provided an overview of the results of the discussions and selected papers presented at the symposium. The CDQ and IJEVG issues actually served as the Symposium proceedings.

The success and international recognition of this first joint IAEVG-NCDA Symposium, as well as the proceedings, convinced the boards of both associations to consider the possibility of organizing a second joint activity. What at the time was only a vague idea took on another form. At the 2005 Society for Vocational Psychology (SVP) biennial conference held in Vancouver, Canada, the then presidents of NCDA, Janet Lenz, and SVP, David Blustein and Paul Gore, together with the IAEVG chair of the first joint Symposium, Raoul Van Esbroeck, discussed the possibility of a new joint symposium sponsored by all three organizations. The observation expressed by several participants at this SVP conference was that at the worldwide level there is a split between vocational psychologists and career guidance practitioners. Participants sensed that this disconnect, or perception of a disconnect, was regrettable and unnecessary. In their view, a new joint symposium on this topic was long overdue. The boards of the three organizations supported these views and appointed a Joint Planning Committee.

The Planning Committee received strong support from Italian colleagues of the University of Padova under the leadership of Salvatore Soresi and Laura Nota, who

\footnotetext{
R. Van Esbroeck $(\bowtie)$

Vrije Universiteit Brussel, Pleinlaan, 2, 1050 Brussel, Belgium

e-mail: rvesbroe@vub.ac.be

J. Trusty

Pennsylvania State University, University Park, PA, USA
} 
chaired the local Organizing Committee. Together, these groups organized the 2007 IAEVG-SVP-NCDA International Symposium on Vocational Psychology and Career Guidance Practice: An International Partnership. This symposium was held on September 3, 2007, in Padua, Italy, alongside the annual IAEVG International Conference.

The Planning Committee considered the publication of the Symposium proceedings as essential for the distribution of the results of the discussion at the Symposium. From the start, they opted for the same format used for the proceedings of the 2004 Symposium, and again proposed the publication of companion issues of the CDQ and the IJEVG. The boards of both journals/organizations supported this option and appointed a guest editorial team representing the three collaborating associations, including Paul Gore (SVP), Jerry Trusty (NCDA) and Raoul Van Esbroeck (IAEVG). Their task was made easier because they could follow the model of the first joint publication. The Career Development Quarterly presents the keynote contribution, the outcomes of the activities in the discussion groups, and the general conclusions, whereas the International Journal for Educational and Vocational Guidance publishes a selection of papers presented in these groups. Unfortunately, page number limitations made it impossible to publish all submitted papers. Once again, our Italian colleagues helped to overcome this problem and made it possible to publish a number of the Symposium papers. They decided to publish a conference book on the IAEVG conference (Nota \& Soresi, in press) and were kind enough to also include a number of the Symposium papers.

Taken together the two issues provide a thorough overview of the results of the discussions, while at the same time presenting selected papers that prompted much discussion. The content of the two journals is described at greater length by the guest editorial team in their Introduction to the Special Issue. Also, a Table of Contents for the two special issues is included in both journals.

We wish you pleasant reading and hope that these publications help to overcome the perceived-though in our opinion non-existent-split between vocational psychology and career guidance practice. For many who were present at the symposium, there was no evident split, rather, a dynamic interplay. We thank all who contributed to the Symposium and the CDQ and IJEVG special issues.

\section{Reference}

Nota, L., \& Soresi, S. (Eds.). (in press). Nuove sfide per l'orientamento scolastico-professionale [New challenges for vocational guidance]. Firenze: Organizzazioni Speciali-Giunti. 